\title{
The Effects of Plyometric Education Trainings on Balance and Some Psychomotor Characteristics of School Handball Team
}

\author{
Zeynep Inci Karadenizli
}

Faculty of Sport Sciences, Duzce University, Turkey

Copyright $(2016$ by authors, all rights reserved. Authors agree that this article remains permanently open access under the terms of the Creative Commons Attribution License 4.0 International License

\begin{abstract}
This study aims to search the effects of plyometric education trainings which was applied for 10-week on static-dynamic balance and some psychomotor characteristics of students who were been handball team of school. The female students-players $(\mathrm{N}=16)$ who are in age $14,57 \pm 0,92$ years. All student have got $3,66 \pm 0,63$ years sport experience. Plyometric education trainings were performed twice a week for 10-week in the trainings of school handball team. Parameters such as body weight, height, vertical jump, standing long jump, 30m speed, agility, flexibility, and static-dynamic balance were measured and anaerobic power was calculated by Lewis formula. The SPSS 15.0 program was preferred for the statistics. Descriptive statistics were used for the analysis of psychomotor characteristics and paired sample t test was used for the differences between the pre-test and post-test of plyometric education training of the players. The significance level was set at 0.05 . The differences were observed between the pre-test and post-test of plyometric education training of flexibility $\mathrm{t}(51)=-4,518$; $\mathrm{p}=0,00$, standing long jump $\mathrm{t}(12)=-8,129 ; \mathrm{p}=0,00$, anaerobic power $\mathrm{t}(01)=-3,018 ; \mathrm{p}=0,05$ and left leg ellipse area at unipedal static balance $\mathrm{t}(39)=2,399 ; \mathrm{p}=0,04$ were found to be statistically significant $(\mathrm{p} \leq 0.05)$.
\end{abstract}

Keywords Anthropometry, Balance, Handball, Physical Education, Psychomotor Characteristics

\section{Introduction}

Motor ability, sprinting, jumping, flexibility and throwing velocity represent physical activities are important for team handball. Handball players are a jumper, thrower, sprinter all in one and must execute these skills with precision and speed. They often perform upper extremity passing, shooting and dribbling skills while wearing shoes on flat stiff surfaces. Their skills require great joint accelerations from jump landings and cutting maneuvers $[1,2,3]$.
Plyometric exercises constitute a natural part of most sport movements because they involve jumping, hopping, and skipping (i.e., such as high jumping, throwing, or kicking). Plyometric training has been advocated as an appropriate approach for sports that require explosiveness and vertical jumping ability enhancement. Generally, plyometric trainings are the best way to provide power / speed to react immediately during the game and also to provide the player to jump higher and to improve the jumping ability of the leg muscles. It provides the opportunity to train specific movement patterns in a biomechanically correct manner at a more functionally appropriate speed. This provides functional strengthening of the muscle, tendon, and ligaments specific to the demands of everyday activities and sports [4]. In these exercises, muscles undergo a rapid elongation followed by an immediate shortening (stretch-shortening contraction), utilizing the elastic energy stored during the stretching phase [30]. Plyometric training does provide such training stimuli and has shown evidence to improve explosive actions in young and pubertal populations [5]. Developing psychomotor characteristics and balance ability by the help of plyometric trainings is only possible on the condition that all these trainings are applied in a training program. This program covers an educational process requiring a well-organized design and application with utmost care. For this reason, in plyometric educational training, time, content, exercise/intensity, frequency of exercises, age groups of participants, equipment selected and drills should be taken into consideration. Especially, these studies of vital importance when applied with children and young participant; or else, some unexpected sports injures may happen easily [26, 27]. That is the reason why the importance of plyometric training education program is overemphasized in this recent study.

Balance is generally defined as the ability to maintain the body's center of gravity within its base of support and can be categorized as either static or dynamic balance. Static balance is the ability to sustain the body in static equilibrium or within its base of support. Dynamic balance is supported 
to be more challenging because it requires the ability to maintain equilibrium during a transition from a dynamic to a static state [6]. Dynamic balance is necessary and effective in the fundamental technical movements of the handball sports such as dribbling, throwing, kicking and faking. The dynamic balance on one leg is also very important for doing the basic movements on handball $[1,35]$. Lower limb joint proprioception is known to play a key role in maintaining normal body posture [7].

Sport training can improve sensorimotor performance and postural control $[8,9]$ and may cause different balance abilities and these differences could be objectively measured using Center of Pressure Measurements (C.o.P) [10]. It is stated that using a combinational plan (plyometric, technical, balance and strength) can improve anterior-posterior balance [11]. Strength, plyometric and combinational trainings improve dynamic balance among athlete students [12]. It is stated that the expertise on gymnastic has an effect on postural control during changing postural situation from two leg standing to one leg standing. In addition, this effect is a result of the ability education $[9,13]$. On the contrary, Seiler et al. (2008) stated that one leg balance was not significantly improved after the intervention training [14].

A lot of factors affect to static and dynamic balance such as motoric and anthropometric characteristics [15], proprioceptive balance and visual clues $[16,17]$, explosive power [18], training programs [15], asymmetries in muscle strength $[19,20]$, experience and training year $[13,21]$. On the other hand, Altinkok (2016) also stated that pre-school children's basic motor movements such as flexibility, standing long jump and static balance performances are improved after 12-week coordination and movement education program [40]. It is seen that plyometric training program has been applied with different drill, time and intensity in previous studies $[12,15,26,28,31,37,38]$, but there were a little study that examined how balance and psychomotor characteristics are affected by plyometric education training program in young female players at school. Therefore, this study aims to search the effects of plyometric education trainings applied for 10 -week on static-dynamic balance and some psychomotor characteristics of students who are been handball team of school.

\section{Materials and Methods}

\subsection{Participants}

The female students-players $(\mathrm{N}=16)$ are in age $14,57 \pm 0,92$ years. All student have got 3,66 $\pm 0,63$ years sport experience. Sixteen adolescent volunteer students without any sports injuries in the last year and visual-sensory disorders were enrolled in the study. The study was approved by the local ethical committee of the Marmara University.

\subsection{Procedures of Psychomotor and Balance Tests}

The players were informed of the psychomotor and balance tests. After the 15 minutes warming up activity, the psychomotor tests were applied at the same day. Before the plyometric education training program, the players were evaluated with speed (30 m sprint test), vertical jump (for anaerobic power), horizontal jump (standing long jump test), agility (Illionis test), flexibility (sit and reach test) static and dynamic balance tests. Following 10 -week training the tests were repeated. Pre-test and post-test results were compared. The players applied this test 2 times to evaluate them. Between the repetitions 2 minutes and between the tests 3 minutes rest intervals were given. The best rates were recorded as the test result. After 2 hours resting time static and dynamic balance tests were measured by Prokin (Prokin System 5.0 Pk-Manop-05-en-01 Bergamo, Italy). Anaerobic power was calculated by Lewis formula $(\sqrt{4} .9 \times$ (Body weight) $\mathrm{x} \sqrt{\mathrm{D}}$ ( $\mathrm{D}=$ jumping distance).

Body weight and height measurements: The measurements of the body weight and height were done with Desis weighting expert digital weighting scale and linear measurement scale.

Speed - 30m sprint test: $30 \mathrm{~m}$ sprint tests measurements were done with Sport Expert MPS 501 photocell devices.

Agility - Illionis test: Illionis agility test were done by the photo celled doors at the starting and finish points.

Vertical jump - Counter movement jump test: The vertical jumping tests were measured with New Test 2000 devices.

Horizontal Jump-Standing long jump test: Standing Jump tests were done with metric measurement method.

Flexibility - Sit and reach test: Flexibility measurement test was done with sit-reach test [22].

Static Balance Tests: After explaining the tests to the subjects, data were entered (height, weight, age) and the device was calibrated. The feet of the subjects were placed on the balance platform nakedly (in a fashion that the distance between feet was 10 centimeters and the projection of the maximum point of the medial arcs was on the $\mathrm{x}$-axis). The subjects were asked to look at the screen in front of them with $10 \mathrm{~cm}$ distance between their feet while their arms were at sides, and to keep them fixed at (0) point. After completion of each test, when the device was being recalibrated, the subject was asked to sit down and rest. At the time of the measurements, no verbal feedback was given to the subjects other than what was necessary (Figure 1).

a) Bipedal (double leg) static balance test: Bipedal static balance were performed for 30 seconds with eyes open (EO) and eyes closed (EC). The data obtained were evaluated in terms of average center of pressure X (C.o.P.X), average center of pressure Y (C.o.P.Y), average forward-backward velocity, average medium-lateral velocity, perimeter, and ellipse area.

b) Unipedal (left / right leg) static balance test: In this test, subject tries to stand up with one legged (left and right) within $30 \mathrm{~s}$ without hold. The data obtained were evaluated 
in terms of average center of pressure X (C.o.P.X), average center of pressure Y (C.o.P.Y), average forward-backward velocity, average medium-lateral velocity, perimeter, and ellipse area (Figure 2).

Dynamic Balance - Slalom Test: Dynamic Slalom test was used as monoaxial dynamic-time test Medio-Lateral (M-L) to one axis a time and to assess the subject's skill to complete the exercise. In this test, the subject tries to see some balls-objectives that come against. The subject's scope is to hit objectives and follow ideal line within 60 seconds duration hold with two hands. Subject load was selected 5 hard degrees (according to soft (0) to hard (10) degree system). At the end of the test, the software provides two results: caught up objectives and the perimeter error. The caught up objectives shows the objectives hit by the subject regarding the total objectives of the test. The perimeter error shows the subject's ability to stay on the blue ideal line. The error is calculated on how much perimeter in more has been store clerk regarding the ideal perimeter (Figure 3).

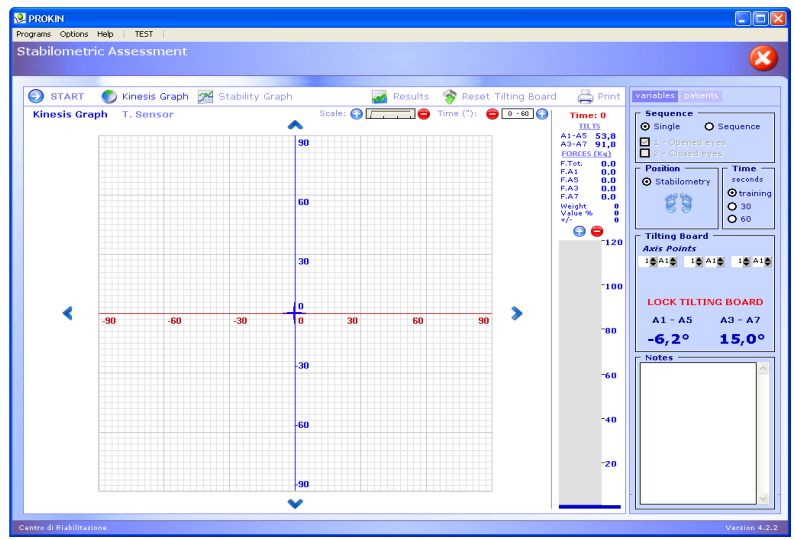

Figure 1. Static Balance test's screen

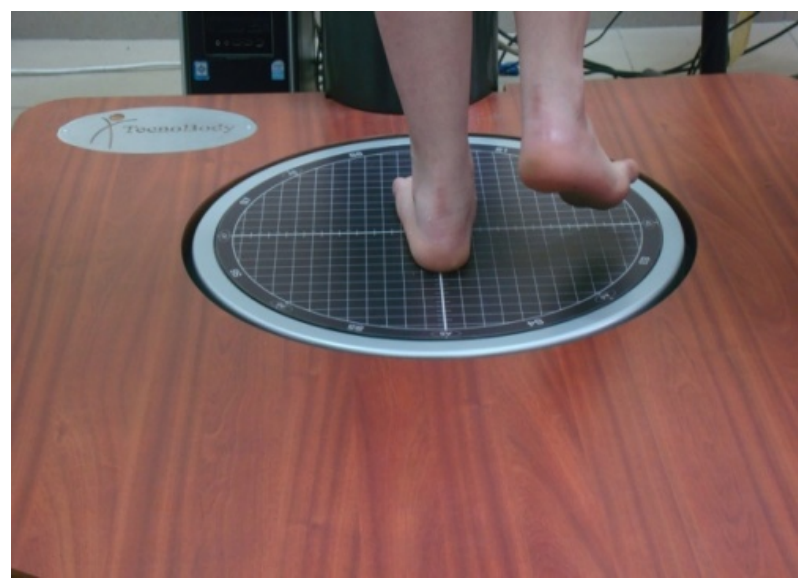

Figure 2. Unipedal (left) static balance test

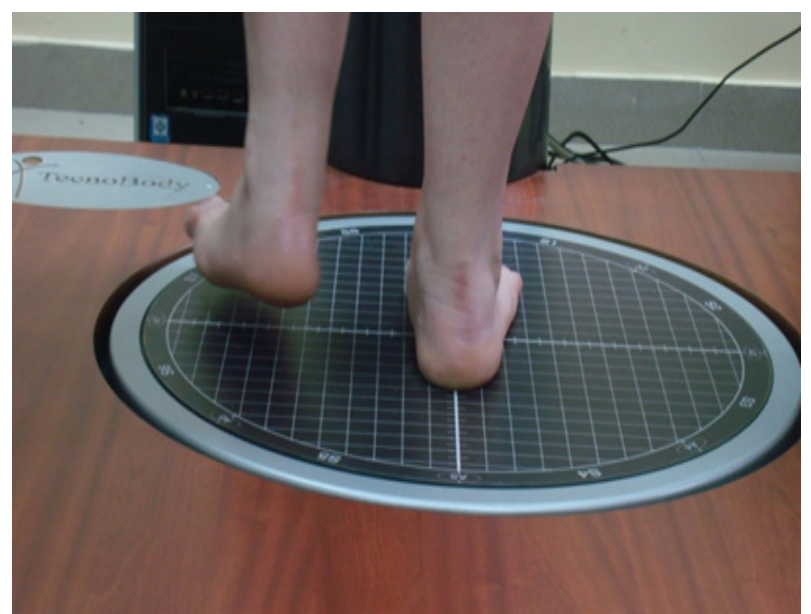

Figure 3. Unipedal (right) static balance test

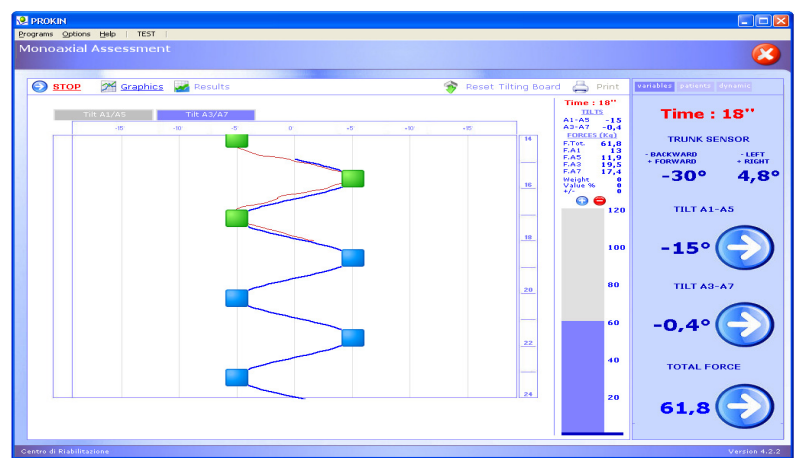

Figure 4. Dynamic balance-slalom test's screen

\subsection{Procedures of Plyometric Education Program}

Plyometric education trainings were performed twice a week for 10 weeks in the trainings of school handball team. This program was applied at least 2 days before the match day and with 2 days apart. The protocol of plyometric education training program was applied with 5 drills, twice in a week. Applying was started after the warming up. First 5 weeks; the exercises were performed in 3 sets. Each set the loading time was 30 seconds. Resting time between the drills was 30 seconds and between the sets 4 minutes. The last 5 weeks; 4 sets were done. Each drill loading time was 40 seconds. Resting time between the drills was 40 seconds and between the sets 5 minutes.

\subsection{Model of Plyometric Education Training Program}

1. Drill: Jumping with two legs from right to left side over $40 \mathrm{~cm}$ bar.

2. Drill: Doing pull-up with $1 \mathrm{~kg}$ health balls. While doing pull-up the player gives the ball to her standing partner.

3. Drill: Jumping forward over 5 bars of $40 \mathrm{~cm}$ with two legs and then $15 \mathrm{~m}$ sprint. After the determined distance, come back by jogging and repetition the exercise.

4. Drill: Arm-over standing passes with $1 \mathrm{~kg}$ health ball with the partner. 
5. Drill: 2 parallel $15 \mathrm{~m}$ lines, which have $80 \mathrm{~cm}$ between them. The player jumps with left foot to left then right foot to the right. After the determined distance, come back and repetition the exercise.

\subsection{Statistical Analysis}

Descriptive statistics were used for the analysis of psychomotor characteristics and paired t test was used for the differences between the pre-test and post-test of plyometric education training of the groups. The SPSS 15.0 program was preferred for the statistics. The significance level was set at 0.05 .

\section{Results}

Sixteen female school handball team's students $14,57 \pm 0,92$ years of age and 3,66 0,63 training years were included to the study (Table 1).
The differences were found between pre-test and post-test values which were been flexibility, standing long jump, anaerobic power and left leg ellipse area at unipedal static balance tests. The differences observed between the pre-test and post-test of plyometric education training of flexibility $\mathrm{t}(51)=-4,518, \mathrm{p}=0,000$, standing long jump $\mathrm{t}(12)=-8,129$, $\mathrm{p}=0,000$, anaerobic power $\mathrm{t}(01)=-3,018, \mathrm{p}=0,005$ and left leg ellipse area at unipedal static balance $\mathrm{t}(39)=2,399, \mathrm{p}=$ 0,043 were found to be statistically significant $(p \leq 0.05)$. It shows that values of flexibility, standing long jump and anaerobic power increase from pre-test to post-test. Value of left leg ellipse area at unipedal static balance decreases from pre-test to post-test are shown in table 2 and table 3 .

No statistically significant difference was found between the pre-test and post-test of plyometric education training for vertical jump, $30 \mathrm{~m}$ speed, agility, dynamic balance, and other measurements about static balance test $(\mathrm{p} \geq 0.05)$ (Table 2,3).

Table 1. Descriptive data

\begin{tabular}{|c|c|c|c|c|}
\hline $\mathrm{N}=16$ & Sport age (year) & Age (year) & Height $(\mathrm{cm})$ & Weight $(\mathrm{kg})$ \\
\hline Mean $\pm \mathrm{SD}$ & $3,66 \pm, 63$ & $14,57 \pm, 92$ & $161,44 \pm 54,41$ & $56,95 \pm 4,45$ \\
\hline
\end{tabular}

Table 2. Paired t test results - psychomotor characteristics tests

\begin{tabular}{|c|c|c|c|c|c|}
\hline Test Parameters & $\mathrm{N}$ & & Mean \pm SD & $\mathrm{t}$ & $\mathrm{p}$ \\
\hline \multirow{2}{*}{ Flexibility (cm) } & \multirow{2}{*}{16} & Pre-test & $24,92 \pm 6,49$ & \multirow{2}{*}{$-4,518$} & \multirow{2}{*}{, $000 *$} \\
\hline & & Post-test & $30,23 \pm 8,22$ & & \\
\hline \multirow{2}{*}{ Standing long jump (cm) } & \multirow{2}{*}{16} & Pre-test & $154,63 \pm 14,61$ & \multirow{2}{*}{$-8,129$} & \multirow{2}{*}{, $000 *$} \\
\hline & & Post-test & $178,38 \pm 15,89$ & & \\
\hline \multirow{2}{*}{$\begin{array}{c}\text { Anaerobic power } \\
(\mathrm{kg}-\mathrm{m} / \mathrm{sn})\end{array}$} & \multirow{2}{*}{16} & Pre-test & $591,63 \pm 83,81$ & \multirow{2}{*}{$-3,018$} & \multirow{2}{*}{, 005 ** } \\
\hline & & Post-test & $631,87 \pm 87,79$ & & \\
\hline \multirow{2}{*}{ Speed (s) } & \multirow{2}{*}{16} & Pre-test & $5,04 \pm 0,86$ & \multirow{2}{*}{$-5,623$} & \multirow{2}{*}{,121 } \\
\hline & & Post-test & $5,03 \pm 0,63$ & & \\
\hline \multirow{2}{*}{ Agility (s) } & \multirow{2}{*}{16} & Pre-test & $17,02 \pm 0,72$ & \multirow{2}{*}{$-7,203$} & \multirow{2}{*}{, 172} \\
\hline & & Post-test & $17,00 \pm 0,54$ & & \\
\hline \multirow{2}{*}{ Vertical jump (cm) } & \multirow{2}{*}{16} & Pre-test & $28,06 \pm 3,75$ & \multirow{2}{*}{$-6,108$} & \multirow{2}{*}{, 252} \\
\hline & & Post-test & $28,78 \pm 2,93$ & & \\
\hline
\end{tabular}


Table 3. Paired t test results - Static \& Dynamic balance tests

\begin{tabular}{|c|c|c|c|c|}
\hline Test Parameters & & Mean \pm SD & $\mathrm{t}$ & $\mathrm{p}$ \\
\hline \multirow{2}{*}{$\begin{array}{l}\text { Bipedal (double leg)- eyes open static balance - average } \\
\text { forward-backward velocity }(\mathrm{mm} / \mathrm{sec})\end{array}$} & Pre-test & $16,35 \pm 2,32$ & \multirow{2}{*}{$-4,601$} & \multirow{2}{*}{.259} \\
\hline & Post-test & $17,23 \pm 4,54$ & & \\
\hline \multirow{2}{*}{$\begin{array}{l}\text { Bipedal (double leg)- eyes open static balance - average } \\
\text { medium-lateral velocity }(\mathrm{mm} / \mathrm{sec})\end{array}$} & Pre-test & $11,78 \pm 3,55$ & \multirow{2}{*}{$-3,556$} & \multirow{2}{*}{.127} \\
\hline & Post-test & $11,94 \pm 4,89$ & & \\
\hline \multirow{2}{*}{$\begin{array}{l}\text { Bipedal (double leg)- eyes open static balance - perimeter } \\
\qquad(\mathrm{mm})\end{array}$} & Pre-test & $618,35 \pm 44,89$ & \multirow{2}{*}{$-2,036$} & \multirow{2}{*}{.458} \\
\hline & Post-test & $594,86 \pm 38,24$ & & \\
\hline \multirow{2}{*}{$\begin{array}{l}\text { Bipedal (double leg)- eyes open static balance - ellipse area } \\
\qquad\left(\mathrm{mm}^{2}\right)\end{array}$} & Pre-test & $601,78 \pm 72,71$ & \multirow{2}{*}{$-2,397$} & \multirow{2}{*}{.602} \\
\hline & Post-test & $724,49 \pm 67,92$ & & \\
\hline \multirow{2}{*}{$\begin{array}{l}\text { Bipedal (double leg)- eyes closed static balance -average } \\
\text { forward-backward velocity }(\mathrm{mm} / \mathrm{sec})\end{array}$} & Pre-test & $19,42 \pm 4,32$ & \multirow{2}{*}{$-3,449$} & \multirow{2}{*}{.386} \\
\hline & Post-test & $21,33 \pm 6,59$ & & \\
\hline \multirow{2}{*}{$\begin{array}{l}\text { Bipedal (double leg)- eyes closed static balance -average } \\
\text { medium-lateral velocity }(\mathrm{mm} / \mathrm{sec})\end{array}$} & Pre-test & $8,5 \pm 3,59$ & \multirow{2}{*}{$-2,962$} & \multirow{2}{*}{.475} \\
\hline & Post-test & $9,2 \pm 4,02$ & & \\
\hline \multirow{2}{*}{$\begin{array}{l}\text { Bipedal (double leg)- eyes closed static balance - perimeter } \\
\qquad(\mathrm{mm})\end{array}$} & Pre-test & $607,00 \pm 38,73$ & \multirow{2}{*}{6,744} & \multirow{2}{*}{.564} \\
\hline & Post-test & $732,24 \pm 44,57$ & & \\
\hline \multirow{2}{*}{$\begin{array}{l}\text { Bipedal (double leg)- eyes closed static balance - ellipse } \\
\qquad \text { area }\left(\mathrm{mm}^{2}\right)\end{array}$} & Pre-test & $431,85 \pm 32,67$ & \multirow{2}{*}{$-3,461$} & \multirow{2}{*}{.192} \\
\hline & Post-test & $418,99 \pm 24,56$ & & \\
\hline \multirow{2}{*}{$\begin{array}{l}\text { Unipedal (right leg) static balance }- \text { average } \\
\text { forward-backward velocity }(\mathrm{mm} / \mathrm{sec})\end{array}$} & Pre-test & $31,78 \pm 7,34$ & \multirow{2}{*}{$-2,531$} & \multirow{2}{*}{.455} \\
\hline & Post-test & $30,73 \pm 6,23$ & & \\
\hline \multirow{2}{*}{$\begin{array}{l}\text { Unipedal (right leg) static balance - average } \\
\text { medium-lateral velocity }(\mathrm{mm} / \mathrm{sec})\end{array}$} & Pre-test & $28,64 \pm 4,21$ & 3050 & 621 \\
\hline & Post-test & $29,88 \pm 5,44$ & $-5,009$ & . 021 \\
\hline Uninedal (rioht leo) static balance - nerimeter (mm) & Pre-test & $1237,50 \pm 934,50$ & -3552 & 396 \\
\hline Unipedal (rignt leg) static balance - perimeter (mm) & Post-test & $1211,86 \pm 862,48$ & -5,JJL & . \\
\hline Uninedal (right leo) static balance_ellinse area $\left(\mathrm{mm}^{2}\right)$ & Pre-test & $1032,00 \pm 741,96$ & -6247 & 284 \\
\hline Unipedal (rignt leg) static balance -ellipse area $\left(\mathrm{mm}^{2}\right)$ & Post-test & $1189,30 \pm 689,70$ & $-0,241$ & .204 \\
\hline Unipedal (left leg) static balance -average & Pre-test & $38,14 \pm 5,48$ & -2345 & 162 \\
\hline forward-backward velocity (mm/sec) & Post-test & $39,07 \pm 6,02$ & נדרנ, & .102 \\
\hline Unipedal (left leg) static balance - average medium-lateral & Pre-test & $32,07 \pm 4,28$ & -4.521 & 201 \\
\hline velocity $(\mathrm{mm} / \mathrm{sec})$ & Post-test & $31,89 \pm 5,46$ & 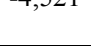 & .201 \\
\hline Uninedal (left leo) static balance - nerimeter (mm) & Pre-test & $1426,00 \pm 348,95$ & 3206 & 231 \\
\hline 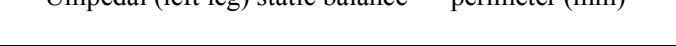 & Post-test & $1501,24 \pm 462,76$ & S, & . 201 \\
\hline Uninedal (left leo $)$ static balance - ellinse area $\left(\mathrm{mm}^{2}\right)$ & Pre-test & $1437,21 \pm 597,97$ & 2399 & $043 *$ \\
\hline Unipedal (lett leg) static balance - ellipse area $\left(\mathrm{mm}^{2}\right)$ & Post-test & $1082,00 \pm 518,91$ & ( & 的 \\
\hline Binedal dvnamic halance - caught un obiectives & Pre-test & $8,21 \pm 3,44$ & -3532 & 146 \\
\hline Dipedar dy & Post-test & $7,92 \pm 2,25$ & - & .140 \\
\hline Binedal dynamic balance - nerimeter error $(0$ & Pre-test & $41,88 \pm 4,59$ & -5864 & 347 \\
\hline 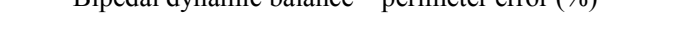 & Post-test & $42,31 \pm 7,86$ & $-5,007$ & 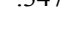 \\
\hline
\end{tabular}

$* \mathrm{p} \leq 0.05$

\section{Discussion}

It is shown that plyometric education training positively affects the flexibility, standing long jump, anaerobic power and left leg ellipse area at unipedal static balance performances $(p \leq 0.05)$. No statistically significant difference is found between the pre-test and post-test of plyometric education training for vertical jump, $30 \mathrm{~m}$ speed, agility, dynamic balance, and other measurements about static balance test $(\mathrm{p} \geq 0.05)$ (Table 2,3).

Flexibility: The result of current study is shown that plyometric education training positively affects flexibility $(\mathrm{p} \leq 0.05)$. Iri et al. (2009) conducted a study on 12-14 year-old kids concerning the effects of football ability trainings on basic motoric characteristics. Statistical significant differences on flexibility were measured [23]. 
This study is in agreement with the result of the current research. It is thought that this analogy is seen because of the fact that similar age groups and team sports players (such as handball players, soccer players, basketball players, etc.) take place in both this study and sample group. On the contrary, Aktas et al. (2011) conducted a study on 12-14 aged male tennis players. After 8 weeks of power training (including plyometric exercises), they stated that there is an insignificant difference between the test and the control group [24]. Hewett et al. (1996) applied the plyometric training program on female athletes and found no significant difference on flexibility measurements [25]. These studies are not in agreement with the result of the current paper. It is also thought that this contrast results from plyometric training program and the effects of sport branches.

Standing long jump: The result of current study is shown that plyometric education training positively affects standing long jump ( $\mathrm{p} \leq 0.05)$. Diallo et al. (2001) studied the effects of 10 -week plyometric training on jump performance on 12-13 aged soccer players. They noted significant longer standing jump values for the study group [26]. Asadi \& Arazi (2012) applied the 6-week high-intensity plyometric training program on young male basketball players and found that standing long jump improved on plyometric group [27]. These studies are in agreement with the result of the current paper. It is thought that cause of this situation that is aroused is sample group included in team sport's players (handball, soccer, basketball) in both studies.

Static and Dynamic Balance: There is a little information about whether the effect of plyometric training can improve balance performance in adults and female [34, 14]. Myer et al. (2006) applied 7-week balance and plyometric training on high school female athletes. They stated that the percent change from pre-test to post-test in vertical ground reaction force was significantly different between the balance and plyometric groups on the dominant side. Both groups decreased their standard deviations of center of pressure (C.o.P) during hop landings in the medial/lateral direction on their dominant side, which equalized pretested side to side differences [34]. Arazi \& Asadi (2011) applied 8-week aquatic and land plyometric training on young male basketball players. They noted that the land plyometric training group indicated better improvement than aquatic plyometric training group in dynamic balance [33].

In the current study, it is shown that plyometric education training positively affects left leg ellipse area at unipedal static balance performances $(p \leq 0.05)$. In the current study, handball player's dominant legs are right and their jumping legs are left. Another result of the current study is that no statistically significant difference has been found between the pre-test and post-test of plyometric education training for dynamic balance, Romberg test and the other measurements about static balance test ( $\mathrm{p} \geq 0.05)$. Arazi \& Asadi (2012) stated that plyometric group made improved their dynamic balance, but this change was not statistically significantly [27]. Asadi (2013a) applied plyometric training took place 2 days a week for 6 weeks including depth jump, vertical jump, and standing long jump on intermediate basketball male players. In conclusions, there were no significant changes $(p>0.05)$ in Star Excursion Balance Test (SEBT), but plyometric group showed $\sim 5 \%$ improvement [39]. These findings support the current study.

Balance is not only important for the execution of complex technical gestures, but it is also connected to the overall athlete's strength, as reported by Cowley [29]. Another research finding proved the effect of 8-week combinational training (strength and plyometric) on dynamic balance of teenage handball players. The highest effect in three groups (strength, plyometric and combinational) were in three directions of posterior-internal, internal and posterior. In addition, it was indicated that as during achievement action in these directions we need Hamstring muscle activity [15]. Myer et al. (2006) also stated that hamstrings strength and vertical jump values are more important during plyometric and balance training [34]. It was stated that there was a significant correspondence between given training programs and static and dynamic balance [32]. It was stated that using a combinational plan (plyometric, technical, balance and strength) can improve anterior-posterior balance [11].

The static and dynamic balance test results gained at the end of the study shows a similarity with the previous ones done by Myer et al. (2006) and Arazi \& Asadi (2011). It is thought that this situation may result from the lack of force and/or combined training besides plyometric studies, and it is also assumed that there may be differences in lower limb muscle strength and applied training programs. On the other hand, dynamic balance test values in this current study shows a similarity with the ones carried out by Arazi \& Asadi (2012) and Asadi (2013). It is thought that these findings in both studies result from the fact that sample group sportsmen consists of players from the team sports players.

Anaerobic power, Vertical jump: The result of current study is shown that plyometric education training positively affects anaerobic power $(\mathrm{p} \leq 0.05)$. Rahimi \& Behpur (2005) stated that plyometric training together with traditional weight-lifting power training supports vertical jump and explosive power performance positively [28]. No statistically significant difference was found between the pre-test and post-test of plyometric education training for vertical jump ( $\mathrm{p} \geq 0.05)$. Nicole et al. (2004), stated that plyometric training studies for 6 weeks, twice a week caused an insignificant increase on vertical jump values [37]. Turner et al. (2003) also showed no significance difference on vertical jump performance after 6 weeks plyometric training [38]. On the contrary, Asadi \& Arazi (2012) applied the 6-week high-intensity plyometric training program on young male basketball players. They stated that the plyometric group made significantly greater improvements than control group in vertical jump [27]. Diallo et al. (2001) stated significant differences between vertical jump performances of young football players before and after 10-weeks plyometric exercises in addition to usual training programs [26]. These studies mentioned above that were done by 
Nicole et al. (2004) and Turner (2003) are in agreement with the result of vertical jump test in the current study. On the other hand, other studies are not in agreement with the result of the current paper. Arazi \& Asadi (2012), Nicole et al. (2004) and Turner et al. (2003) applied plyometric training at the same period (6-week) in their study, but only Arazi \& Asadi (2012) stated that significant difference was found in their study. On the other hand, 10 weeks plyometric training program were used in the study of Diallo et al. (2001) and the recent study for research time plan. Although the plyometric training program period of these studies were the same, the results were found different. It can be said that the content of plyometric training program that were used in the studies is effective on the results). In addition, it is likely that if traditional weight-lifting power training mentioned above [28] had applied as well as plyometric training, significant result would have found.

30m Speed, Agility: Despite the fact that there was an increase in agility and speed values due to the training, no statistically significant difference was found between pre and post-test values ( $\mathrm{p} \geq 0.05)$. On the contrary, it is stated that in season 6-week high-intensity plyometric training can positively affect sprint and agility performance on young male basketball players (aged: 19,1 yrs ; 20,2 yrs ; 20,1 yrs respectively) [27, 36, 39]. These studies were not in agreement with the current study. It is thought that the cause of this situation occurred is sample group included in different ages. In addition, it is likely that plyometric training program included in different intensity. For this reason, increasing agility and speed values are not sufficient in the current study. It can be said that in the recent study, 10-week plyometric education training program included throwing, sprinting, vertical and horizontal jumping movements positively affects to standing long jump, flexibility, anaerobic power and unipedal-static balance performances of adolescent students.

\section{Conclusions}

It is said that results of studies interested in physical education can be affected in some conditions such as age, sport branch, period, content and intensity of exercise. For this reason, it should be careful while prepare and apply to plyometric education training program because of physical education is an important process. In the current study, it is seen that 10 -week plyometric education training program positively affects to flexibility, standing long jump, anaerobic power and left leg ellipse area at static balance performances on adolescent students been handball players. It is estimated that if the physical education curriculum program included plyometric education training program is in school, all students can be benefited from useful results of studies.

\section{REFERENCES}

[1] Rannou F., Prioux J., Zouhal H. \& Gratas-Delamarche P. (2001). Physiological profile of handball players. J. Sports Med. Phys. Fitness., Sep; 41(3), 349-353.

[2] Zapartidis I. (2009). Profile of young female handball players by playing position. Serbian J Sports Sci. 3(1-4), 53-60.

[3] Spori G., Vuleta D., Vuleta D. Jr. \& Dragan M. (2010). Fitness Profiling in Handball: Physical and Physiological Characteristics of Elite Players. Coll. Antropol. 3, 34.

[4] Wilkerson G.B, Colston M.A. \& Short N.I (2004). Neuromuscular changes in female collegiate athletes resulting from a plyometric jump-training program. J Athl Train 39, 17-23.

[5] Vissing K., Brink M., Lønbro S., Sørensen H., Overgaard K., Danborg K., Mortensen J., Elstrøm O., Rosenhøj N., Ringgaard S., Andersen J.L. \& Aagaard P. (2008). Muscle adaptations to plyometric vs. resistance training in untrained young men. J Strength Cond Res 22, 1799-1810.

[6] Ross S.E. \& Guskiewicz K.M. (2004). Examination of static and dynamic postural stability in individuals with functionally stable and unstable ankles. Clinical Journal of Sport Medicine, 14, 332-338.

[7] Gardner E.R., Martin J.H. \& Jessell T.M. The bodily senses. In: Kandel ER, Schwartz JH, Jessell TM, (Ed). Principles of neural science, 4th ed. New York: McGraw-Hill, 2000, pp. $430-449$.

[8] Anderson K. \& Behm D.G. (2005). The impact of instability resistance training on balance and stability. Sports Med, 35, $43-53$.

[9] Vuillerme N. \& Nougier V. (2004). Attentional demand for regulating postural sway: the effect of expertise in gymnastics. Brain Research Bulletin, 63, 161-165.

[10] Gerbino G.P, Griffin E.D. \& Zurakowski D. (2007). Comparison of standing balance between female collegiate dancers and soccer players. Gait \& Posture, 26(4), 501-507.

[11] Paterno M.V., Myer G.D., Ford K.R. \& Hewett T.E. (2004). Neuromuscular training improves single-limb stability in young female athletes. J. Orthop Sports Phys ther, 34(6), 305-16.

[12] Sadeqi H., Hamdollah H., Rostamkhani H. \& Bashiri M. The effect of six-weeks strength, plyometric and combinational trainings (strength and plyometric) on dynamic balance of male athlete students. A research on sport science: 1988, 111-123.

[13] Vuillerme N., Danion F., Marin L., Boyadjian A., Prieur J.M., Weise I. \& Nougier V. (2001). The effect of expertise in gymnastics on postural control. Neurosci Lett, 303, 8386.

[14] Seiler S. \& Saeterbakken A. (2008). A unique core stability training program improves throwing velocity in female high school athletes. Medicine and Science in Sports and Exercise, $40(5), 25$.

[15] Salehzadeh K., Karimiasl A., Borna S. \& Shirmohammadzadeh M. (2011). The effects of 8-week 
plyometric and combinational trainings on dynamic balance of teenage handball players. J Basic Appl Sci Res, 1(12), 3316-3321.

[16] Carolyn A., Emery J., Cassidy D., Terry P., Klassen Rhonda J. \& Rosychuk Brian H. (2005). Effectiveness of a home-based balance training program in reducing sports-related injuries among healthy adolescents: a cluster randomized controlled trial. CMAJ, 172(6): 749-754.

[17] Gioftsidou A., Malliou P., Sofokleous P., Pafis G., Beneka A. \& Godolias G. (2012), The effects of balance training on balance ability in handball players. Exercise and Quality of Life, 4(2), 15-22.

[18] Atilgan Erkut O. (2013). Effects of tramboline training on jump, leg strength, static and dynamic balance of boys. Science of Gymnastics Journal, 5(2), 15-25.

[19] Rahnama N., Lees A. \& Bambaecichi E. (2005). Comparison of muscle strength and flexibility between the preferred and nonpreferred leg in English soccer players. Ergonomics, 48(11-14), 1568-1575.

[20] Schuepfer N., Lembert S., Raschner C., Platzer H.P., Niederkofler A. \& Patterson C. Bilateral differences in electromyographic responses of thigh and knee muscles during repeated maximal isokinetic knee extension and flexion in soccer players. Abstract Band of the 5th International Conference on Strength Training, Odense, 2006.

[21] Paillard T., Noe F., Riviere T., Marion V., Montaya R. \& Dupui P. (2006). Postural performance and strategy in the unipedal stance of soccer players at different levels of competition. Journal of Athletic Training, 41(2), 172-176.

[22] Zorba E. \& Saygin O. (2009). Fiziksel Aktivite ve Uygunluk, Inceler Ofset, Ankara.

[23] Iri R., Sevinc H. \& Suel E. (2009). 12-14 yas grubu cocuklara uygulanan futbol beceri antrenmaninin temel motorik ozelliklere etkisi. Uluslararası Insan Bilimleri Dergisi, Erisim: http://www.insanbilimleri.com

[24] Aktas F. (2011). Kuvvet antrenmanının 12-14 yaş grubu erkek teniscilerin bazı motorik özelliklerine etkisi. Nigde Universitesi Beden Egitimi ve Spor Bilimleri Dergisi 5(1).

[25] Hewett T.E., Stroupe A.L., Nance T.A. \& Noyes F.R. (1996). Plyometric Training In Female Athletes. American Journal of Sports Medicine, 24, 765-772.

[26] Diallo O., Dore E., Duche P. \& Van Praagh E. (2001). Effects of plyometric training followed by a reduced training program on physical performance in prepubescent soccer players. Journal Sports Medicine Physical Fitness, 41, 42-8.

[27] Asadi A. \& Arazi H. (2012). Effects of high-intensity plyometric training on dynamic balance, agility, vertical jump and sprint performance in young male basketball players. Journal of Sport and Health Research, 4(1), 35-44.

[28] Rahimi R. \& Behpur N. (2005). The effects of plyometric, weight and plyometric-weight training on anaerobic power and muscular strength. Physical Education and Sport, 3(1), $81-91$.

[29] Cowley H.R, Ford K. R, Myer G.D, Kernozek T. W. \& Hewett T.E. (2006). Differences in neuromuscular strategies between landing and cutting tasks in female basketball and soccer athletes. Journal of Athletic Training, 41, 67-73.

[30] Markovic G. (2007). Does plyometric training improve vertical jump height? A meta-analytical review. Br J Sports Med., 41:349-355.

[31] Schneiders A.G., Sullivan S.J., Handcock P., Gray A. \& McCrory P.R. (2012). The effect of exercise on dynamic and static balance. Scandinavian Journal of Medicine \& Science in Sports, 22(1), 85-90.

[32] Arazi \& Asadi. (2011). The effect of aquatic and land plyometric training on strength, sprint, and balance in young basketball players. Journal of Human Sport \& Exercise 6(1), 101-111.

[33] Myer G.D., Ford K. R., Brent J.L. \& Hewett T.E. (2006). The effects of plyometric vs dynamic stabilization and balance training on power, balance, and landing force in female athletes. Journal of Strength and Conditioning Research, 20(2), 345-353.

[34] Karadenizli Z.I., Erkut O., Ramazanoglu N., Uzun S., Camliguney A.F., Bozkurt S., Tiryaki C., Kucuk V. \& Sirmen B. (2014). Comparison of dynamic and static balance in adolescents handball and soccer players. Turkish Journal of Sport and Exercise 16(1), 47-54.

[35] Asadi A. (2013b). Effects of in-season plyometric training on jumping and agility performance of basketball players. Sport Sciences for Health 9(3), 133-137.

[36] Nicole J. Chimera, Katleen A., Swanik C. \& Stephen Straub J. (2004). Effects of plyometric training on muscle-activation strategies and performance in female athletes. J Athl Train. Jan-Mar; 39(1), 24-31.

[37] Turner A.M., Owings M. \& Schwane J.A. (2003). Improvement in running economy after 6 weeks of plyometric training. Journal of Strength and Conditioning Research, 17(1), 60-67.

[38] Asadi A. (2013a). Effects of in-season plyometric training on sprint and balance performance in basketball players. Sport Science 6(1), 24-27.

[39] Antinkok M. (2016). The effects of coordination and movement education on pre-school children's basic motor skills improvement. Universal Journal of Educational Research 4(5), 1050-1058. 